\title{
Propofol inhibits burn injury-induced hyperpermeability through an apoptotic signal pathway in microvascular endothelial cells
}

\author{
K.Y. $\operatorname{Tian}^{1 *}$ X.J. Liu ${ }^{2 *}$, J.D. Xu${ }^{1}$, L.J. Deng ${ }^{1}$ and G. Wang ${ }^{1}$ \\ ${ }^{1}$ Department of Anesthesiology, Guangdong General Hospital, Guangdong Academy of Medical Sciences, Guangzhou, China \\ ${ }^{2}$ Department of Anesthesia, Nanfang Hospital, Southern Medical University, Guangzhou, China
}

\begin{abstract}
Recent studies have revealed that an intrinsic apoptotic signaling cascade is involved in vascular hyperpermeability and endothelial barrier dysfunction. Propofol (2,6-diisopropylphenol) has also been reported to inhibit apoptotic signaling by regulating mitochondrial permeability transition pore (mPTP) opening and caspase-3 activation. Here, we investigated whether propofol could alleviate burn serum-induced endothelial hyperpermeability through the inhibition of the intrinsic apoptotic signaling cascade. Rat lung microvascular endothelial cells (RLMVECs) were pretreated with propofol at various concentrations, followed by stimulation with burn serum, obtained from burn-injury rats. Monolayer permeability was determined by transendothelial electrical resistance. Mitochondrial release of cytochrome $\mathrm{C}$ was measured by ELISA. Bax and Bcl-2 expression and mitochondrial release of second mitochondrial-derived activator of caspases (smac) were detected by Western blotting. Caspase-3 activity was assessed by fluorometric assay; mitochondrial membrane potential $\left(\Delta \psi_{\mathrm{m}}\right)$ was determined with JC-1 (a potential-sensitive fluorescent dye). Intracellular ATP content was assayed using a commercial kit, and reactive oxygen species (ROS) were measured by dichlorodihydrofluorescein diacetate (DCFH-DA). Burn serum significantly increased monolayer permeability $(P<0.05)$, and this effect could be inhibited by propofol $(P<0.05)$. Compared with a sham treatment group, intrinsic apoptotic signaling activation - indicated by Bax overexpression, Bcl-2 downregulation, $\Delta \psi_{\mathrm{m}}$ reduction, decreased intracellular ATP level, increased cytosolic cytochrome $C$ and smac, and caspase- 3 activation - was observed in the vehicle group. Propofol not only attenuated these alterations $(P<0.05$ for all), but also significantly decreased burn-induced $R O S$ production $(P<0.05)$. Propofol attenuated burn-induced RLMVEC monolayer hyperpermeability by regulating the intrinsic apoptotic signaling pathway.
\end{abstract}

Key words: Burn injury; Hyperpermeability; Propofol; Apoptosis; Endothelial cells

\section{Introduction}

Burns are a common form of traumatic injury and are associated with high mortality and morbidity rates $(1,2)$. Resulting from endothelial barrier dysfunction and increased vascular hyperpermeability, blister and edema are considered to be classical signs in burn injury $(3,4)$. Microvascular hyperpermeability leads to shifts and losses of fluid from the circulation, and hypovolemia can occur after large burns if massive volume resuscitation is absent. Although adequate fluid resuscitation can improve the hypovolemia, it can also markedly aggravate the edema process if vascular hyperpermeability persists. Therefore, reversing vascular hyperpermeability plays a key role in protecting cells from burn injury.
Some recent studies have suggested that the intrinsic apoptotic signaling cascade is involved in endothelial dysfunction, which is closely associated with vascular hyperpermeability $(5,6)$. In the intrinsic apoptotic pathway, activated mitochondria release cytochrome $\mathrm{C}$ and second mitochondrial-derived activator of caspases (smac), and finally caspase- 3 is activated (7). These mitochondrial factors are regulated by proapoptotic and antiapoptotic Bcl- 2 family proteins, such as Bax/Bak and Bcl-2/Bcl-xL. In endothelial cells, caspase- 3 can cleave $\beta$-catenin resulting in the dissociation of the vascular endothelial (VE)-cadherin- $\beta$ catenin complex (8), which could induce microvascular hyperpermeability (9).

Correspondence: Gang Wang: <gangwang_edu@163.com>.

${ }^{*}$ These authors contributed equally to this study.

Received May 27, 2014. Accepted November 11, 2014. First published online March 6, 2015. 
Propofol (2,6-diisopropylphenol) is a widely used shortacting intravenous anesthetic, and has shown some antioxidative and anti-inflammatory effects (10-12). Furthermore, propofol also has an inhibitory effect on apoptotic signaling through regulating mitochondrial permeability transition pore (mPTP) opening, which is a crucial component of intrinsic apoptotic signal transduction and caspase- 3 activation $(13,14)$. In the present study, we demonstrated that propofol could restore burn serum-induced endothelial hyperpermeability via regulating the intrinsic apoptotic signaling cascade.

\section{Material and Methods}

\section{Animal model and serum collection}

The procedures used in this study and the handling of study animals followed the National Institutes of Health Guidelines on the use of experimental animals. The experimental protocol was approved by the Committee on Research Animal Use of Guangdong Provincial People's Hospital. Male Sprague-Dawley rats $(n=24)$ weighing 180$220 \mathrm{~g}$ were purchased from the Experimental Animal Center of Guangdong Province and allowed to acclimatize for 1 week before experiments. Animals had ad libitum access to chow and water. All the rats were intramuscularly anesthetized using $30 \mathrm{mg} / \mathrm{kg}$ sodium pentobarbital (Shanghai Chemical Plant Co., Ltd., China). Thermal injury was inflicted with a modified Walker and Mason burn model (15). Briefly, a dorsal area equal to $25 \%$ total body surface area (TBSA) was shaved. The rats were placed in a housing with an adjustable opening that exposed the shaved area to $100^{\circ} \mathrm{C}$ water for $30 \mathrm{~s}$. According to the Parkland burn formula, Ringer's lactate solution ( $\left.4 \mathrm{~mL} \cdot \mathrm{kg}^{-1} \cdot \% \mathrm{TBSA}^{-1}\right)$ was constantly infused through a jugular vein cannula to mimic clinical conditions of fluid resuscitation. The rats in a sham treatment group were exposed to water at room temperature for $30 \mathrm{~s}$. Three hours later, blood samples were collected and centrifuged at $1200 \mathrm{~g}$ for $10 \mathrm{~min}$ to harvest the sera, which were then diluted four-fold with phosphate-buffered saline (PBS) and used immediately.

\section{Monolayer permeability}

Rat lung microvascular endothelial cells (RLMVECs, ScienCell, USA) were cultured in DMEM/F12 containing $10 \%$ fetal bovine serum at $37^{\circ} \mathrm{C}$ in a humidified atmosphere with $5 \% \mathrm{CO}_{2}$ for $48 \mathrm{~h}$ to form a confluent monolayer. In a preliminary, time-dependent experiment, monolayers were exposed to serum collected from both the sham treatment and burn groups at 1,2 , or $3 \mathrm{~h}$ postsham/burn. Subsequently, the 3-h postburn serum was used in the following experiments. To determine the effect of propofol on monolayer hyperpermeability, monolayer cells were pretreated with 1,10 , or $50 \mu \mathrm{M}$ propofol for $1 \mathrm{~h}$ before exposure to sham or burn serum. Intralipid (Shanghai Chemical Plant Co., Ltd.) was selected as the vehicle. Endothelial permeability was measured $2 \mathrm{~h}$ after stimulation.

\section{Transendothelial electrical resistance}

The transendothelial electrical resistance (TER) of RLMVEC monolayers was determined with an STX2 electrode and epithelial volt-ohm meter (EVOM2) according to the manufacturer's instructions (World Precision Instruments, USA) (16). RLMVECs were seeded at a density of $1 \times 10^{5}$ cells $/ \mathrm{cm}^{2}$ on fibronectin-coated, $6.5 \mathrm{~mm}$ Transwell filters $(0.4 \mathrm{~mm}$ pore size) and cultured until reaching full confluency. Resistance values of multiple Transwell inserts were measured sequentially in each experimental group and the mean is reported as $\Omega \mathrm{cm}^{2}$ after subtracting the value of a blank cell-free filter.

\section{Measurement of cytosolic cytochrome C}

Cytosolic cytochrome $\mathrm{C}$ content was assayed with a cytochrome C ELISA kit (MBL, USA) (17). RLMVECs were pretreated with intralipid or $10 \mu \mathrm{M}$ propofol and exposed to sham or burn serum. After treatment, cells were lysed in the cold preparation buffer included in the ELISA kit. Cell homogenates were centrifuged $(10,000 \mathrm{~g}$ for $60 \mathrm{~min}$ at $4^{\circ} \mathrm{C}$ ) and the supernatant was collected. Protein concentration was assayed by the bicinchoninic acid assay (BCA). The samples were then treated with a conjugate reagent, and transferred to a cytochrome $\mathrm{C}$ antibody-coated microwell plate and incubated for $60 \mathrm{~min}$ at room temperature. Next, the plate was washed and treated with a substrate reagent and incubated for $30 \mathrm{~min}$, followed by the addition of stop solution. The absorbance was read at $450 \mathrm{~nm}$ with an automatic microplate reader (Spectra Max, M5; Molecular Devices, USA). Serial dilutions of a cytochrome C calibrator were assayed along with the samples to establish a standard curve, which was used to calculate the concentration of cytochrome $\mathrm{C}$.

\section{Measurement of smac}

Cytosol fractions were collected as described above for cytosolic cytochrome C measurement. Smac expression was measured by immunoblotting. An equal amount of protein solution from various treatments was loaded and analyzed by $12 \%$ sodium dodecyl sulfate polyacrylamide gel electrophoresis (SDS-PAGE). After electrophoresis, proteins were transferred onto polyvinylidene fluoride membranes and blotted with primary antibodies against smac (Abcam, UK) and glyceraldehyde 3-phosphate dehydrogenase (GAPDH; Tianjin Sungene Biotech Co., Ltd., China). Membranes were then incubated with horseradish peroxidase-tagged secondary antibody (Earth, USA), and signals were developed by an enhanced chemiluminescence reagent.

\section{Measurement of caspase- 3 activity}

RLMVECs were pretreated with intralipid or $10 \mu \mathrm{M}$ propofol and exposed to sham or burn serum. Caspase-3 activity was assayed with a caspase- 3 activity assay kit (Sigma, USA). The cell homogenates were centrifuged at $10,000 \mathrm{~g}$ for $60 \mathrm{~min}$, and the supernatant was collected for 
caspase- 3 assay. Then, the caspase- 3 activity was measured using the caspase-3/CPP32 fluorometric assay kit (Sigma, USA) following the manufacturer's instructions.

\section{Detection of $\mathrm{Bcl}-2$ and Bax expression}

RLMVECs were pretreated with intralipid or $10 \mu \mathrm{M}$ propofol and exposed to sham or burn serum. Cells were then homogenized and analyzed for $\mathrm{Bcl}-2$ and Bax by Western blotting as described above.

\section{Measurement of mitochondrial membrane potential}

Mitochondrial membrane potential $\left(\Delta \psi_{\mathrm{m}}\right)$ was assayed by staining with the potential-sensitive fluorescent dye JC-1 (Sigma) and detected by flow cytometry (18). JC-1 (5 $\mu \mathrm{mol} / \mathrm{L})$ was loaded on RLMVECs for $15 \mathrm{~min}$ at $37^{\circ} \mathrm{C}$. The stained cells were washed with PBS, and analyzed by flow cytometry (Becton Dickinson FACScan, USA). A minimum of 10,000 cells per sample was analyzed. JC-1 monomers emit at $527 \mathrm{~nm}$ and "J-aggregates" emit at $590 \mathrm{~nm}$. The percentage of cells with abnormally low $\Delta \Psi \mathrm{m}$ (green fluorescence) was determined.

\section{Measurement of cellular ATP}

Intracellular ATP was assayed with a luciferase-based assay kit (CellTiter-Glo, Promega, USA) (18). Cells were seeded and treated on a standard opaque-walled 96-well plate. CellTiter-Glo reagent was added to the wells and allowed to react with cell lysate for $10 \mathrm{~min}$ at room temperature. The luminescence was recorded with an automatic microplate reader (SpectraMax M5; Molecular Devices)

\section{Measurement of ROS levels}

Intracellular reactive oxygen species (ROS) levels were assessed with a dichlorodihydrofluorescein diacetate (DCFH-DA) probe (Sigma) (19). Cells were treated with DCFH-DA $(10 \mu \mathrm{M})$, followed by the stimulation with sham/ burn serum for $20 \mathrm{~min}$ at $37^{\circ} \mathrm{C}$. After incubation, the cells were washed and analyzed using an automatic microplate reader (Spectra Max, M5; Molecular Devices). The relative intensity of DCF fluorescence was measured at a wavelength of $535 \mathrm{~nm}$ and compared with the sham treatment group.

\section{Statistical analysis}

All data are reported as means $\pm S D$. Differences between groups were analyzed by one-way analysis of variance (ANOVA) with the least significant difference (LSD) multiple-comparison test and Student's $t$-test, when appropriate. $\mathrm{P}<0.05$ was considered to be significant.

\section{Results}

\section{Propofol attenuated burn serum-induced monolayer hyperpermeability}

RLMEVC monolayer hyperpermeability was measured

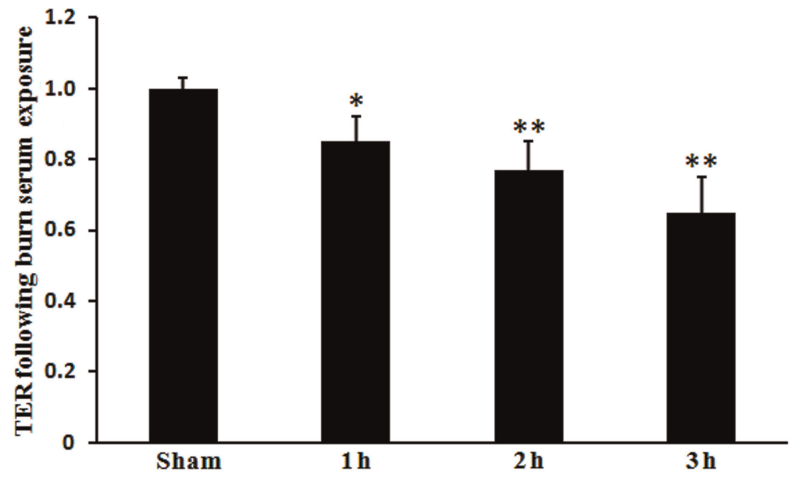

Figure 1. Effect of burn injury on rat lung microvascular endothelial cells (RLMVEC) monolayer permeability. TERs (normalized transendothelial electrical resistance) are shown for each group. RLMVEC monolayers were treated with serum from sham or burn rats 1, 2 or $3 \mathrm{~h}$ post-burn. Monolayer permeability increased significantly at each time point in the burn serumtreated cells compared with the sham serum-treated cells. Data are reported as means $\pm S D\left(n=5\right.$ in each group). ${ }^{*} P<0.05$, ${ }^{* *} \mathrm{P}<0.01$, compared to the sham group (one-way ANOVA).

by detecting the TER of cell monolayers. As shown in Figure 1, a significant increase of monolayer permeability was observed in RLMECs treated with serum at all the time points postsham/burn $(\mathrm{P}<0.05$ or $\mathrm{P}<0.01)$. Serum from sham-burn rats did not induce RLMVEC monolayer hyperpermeability $(P>0.05)$. The increase in monolayer hyperpermeability induced by burn serum stimulation was significantly attenuated by 10 and $50 \mu \mathrm{M}(\mathrm{P}<0.01)$, but not by $1 \mu \mathrm{M}(\mathrm{P}>0.05)$ propofol pretreatment (Figure 2$)$.

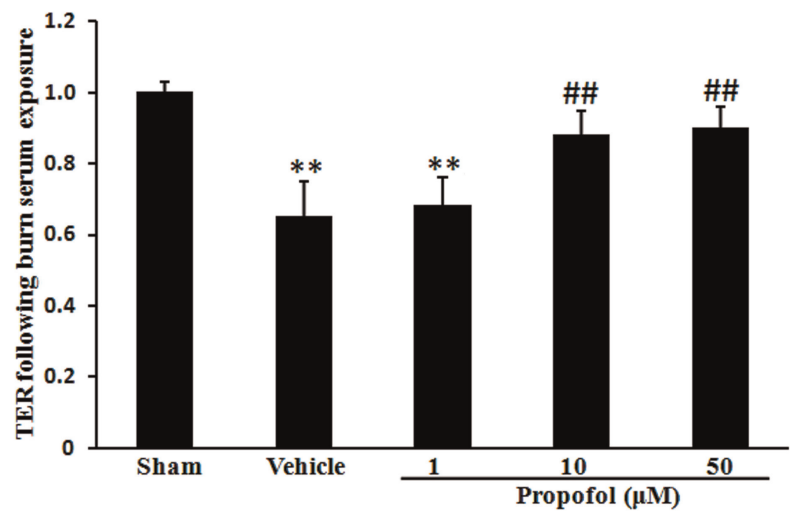

Figure 2. Effect of propofol on burn serum-induced monolayer hyperpermeability. Burn serum significantly increased monolayer permeability compared with sham serum-treated cells. Monolayer permeability was reflected by transendothelial electrical resistance (TER). Compared with burn serum-treated cells, propofol $(10$ and $50 \mu \mathrm{M})$ pretreatment maintained permeability at nearsham levels. Data are reported as means \pm SD $(n=5$ in each group). ${ }^{* *} \mathrm{P}<0.01$, compared to the sham group; ${ }^{\# \# ~} \mathrm{P}<0.01$ compared to the vehicle group (one-way ANOVA). 


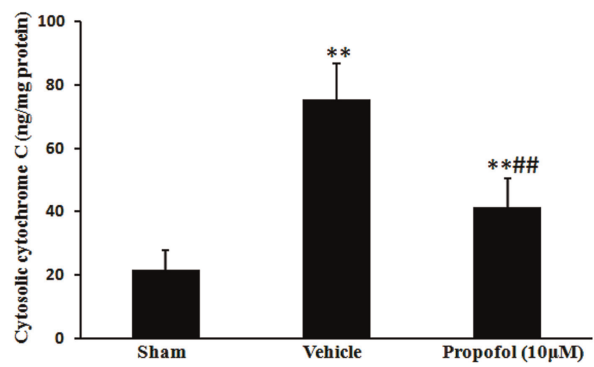

Figure 3. Effect of propofol on burn serum-induced cytochrome $\mathrm{C}$ release. Burn serum induced translocation of cytochrome $C$ from mitochondria into the cytosol. Propofol pretreatment significantly inhibited this translocation. Data are reported as means $\pm S D$ ( $n=5$ in each group). ${ }^{* *} \mathrm{P}<0.01$, compared to the sham group; $\# \# P<0.01$ compared to the vehicle group (one-way ANOVA).

\section{Propofol inhibited burn serum-induced cytochrome $\mathrm{C}$ release}

The cytosolic cytochrome $C$ level in the sham group was $21.4 \pm 6.3 \mathrm{ng} / \mathrm{mg}$ protein, and reached $75.3 \pm 11.6 \mathrm{ng} / \mathrm{mg}$ protein in the vehicle group $(\mathrm{P}<0.01)$. The increase of cytosolic cytochrome $C$ induced by burn serum was significantly reduced to $41.5 \pm 9.1 \mathrm{ng} / \mathrm{mg}$ protein by $10 \mu \mathrm{M}$ propofol pretreatment $(P<0.05$; Figure 3$)$. These results revealed that propofol attenuated the burn serum-induced release of cytochrome $\mathrm{C}$ from mitochondria to cytosol.

Propofol inhibited burn serum-induced smac release

Release of smac from mitochondria into the cytosol normally occurs after the opening of MPTPs. As shown in
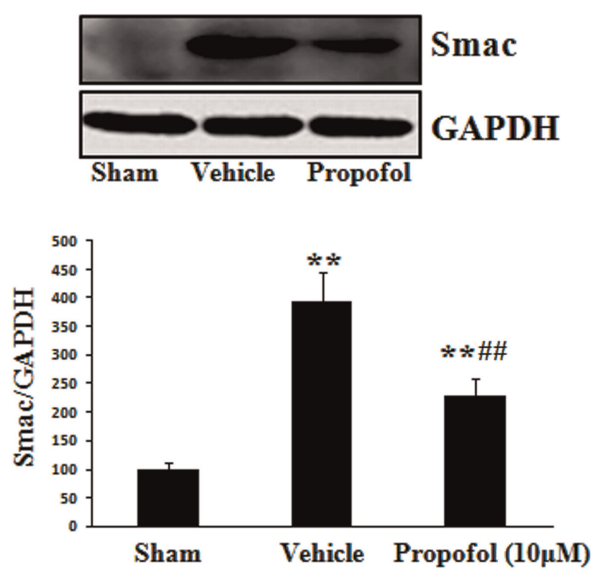

Figure 4. Effect of propofol on burn serum-induced second mitochondrial-derived activator of caspases (smac) release. Compared with the sham group, smac cytosolic content increased after burn serum exposure. Propofol pretreatment led to decreased smac content compared with burn serum-exposed cells. Data are reported as means $\pm S D$ ( $n=5$ in each group). ${ }^{* *} \mathrm{P}<0.01$, compared to the sham group; ${ }^{\# \#} \mathrm{P}<0.01$ compared to the vehicle group (one-way ANOVA).

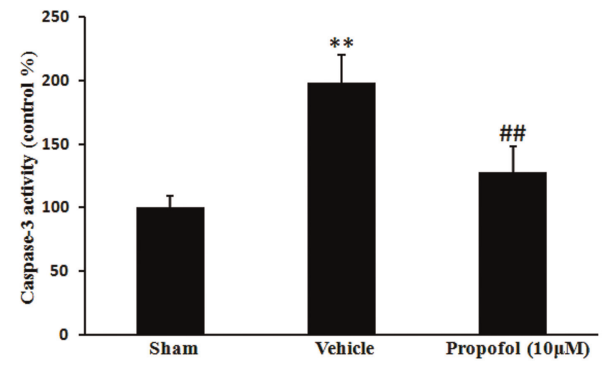

Figure 5. Effect of propofol on burn serum-induced caspase-3 activation. Compared with sham cells, burn serum significantly increased caspase- 3 activity. Propofol treatment inhibited the burn serum-induced increase in caspase- 3 activity. Data are reported as means $\pm S D\left(n=5\right.$ in each group). ${ }^{* *} P<0.01$, compared to the sham group; ${ }^{\# \#} \mathrm{P}<0.01$ compared to the vehicle group (one-way ANOVA)

Figure 4, compared with the sham group, smac content in the vehicle group was significantly increased $(395.3 \pm 51.6 \%$ of the normal values in the sham group, $\mathrm{P}<0.01)$. This increase was significantly inhibited by $10 \mu \mathrm{M}$ propofol pretreatment $(228.7 \pm 30.5 \%$ of normal values in the sham group; $\mathrm{P}<0.01)$. These data indicated that $10 \mu \mathrm{M}$ propofol inhibited burn serum-induced release of smac from mitochondria into the cytosol.

\section{Propofol inhibited caspase- 3 activity induced by burn serum}

Activation of caspases plays a central role in the process of apoptosis. Caspase-3 activity in cells exposed to burn serum was significantly higher than in cells exposed to serum from the sham treatment group $(198 \pm 21.8 \%$ of normal values in the sham group, $\mathrm{P}<0.01)$. This increase was inhibited by $10 \mu \mathrm{M}$ propofol treatment $(128 \pm 19.9 \%$ of normal values in the sham group, $\mathrm{P}<0.05$ ), suggesting that propofol could inhibit the burn serum-induced caspase-3 activation (Figure 5).

\section{Propofol promoted burn serum-induced Bax upregulation and $\mathrm{Bcl}-2$ downregulation}

In the vehicle group, Bax and $\mathrm{Bcl}-2$ expression were $279 \pm 33.3$ and $51 \pm 9.9$, respectively $(P<0.01)$. In propofol-treated cells, Bax expression decreased to $174 \pm 29.1$ $(\mathrm{P}<0.05)$, and $\mathrm{Bcl}-2$ expression increased to $82 \pm 13.7$ $(P<0.01)$. These results revealed that propofol promoted burn-induced Bax upregulation and $\mathrm{Bcl}-2$ downregulation (Figure 6).

\section{Propofol inhibited burn serum-induced loss of $\Delta \psi_{m}$}

RLMEVC $\Delta \psi_{m}$ was determined by flow cytometry, using the potential-sensitive fluorescent dye JC-1. As shown in Figure 7, compared with the sham group, burn serum stimulation effectively increased mitochondrial membrane potential from $14.6 \pm 6.9$ to $63.5 \pm 10.3 \%(P<0.01)$. However, the effect induced by burn serum was partially 


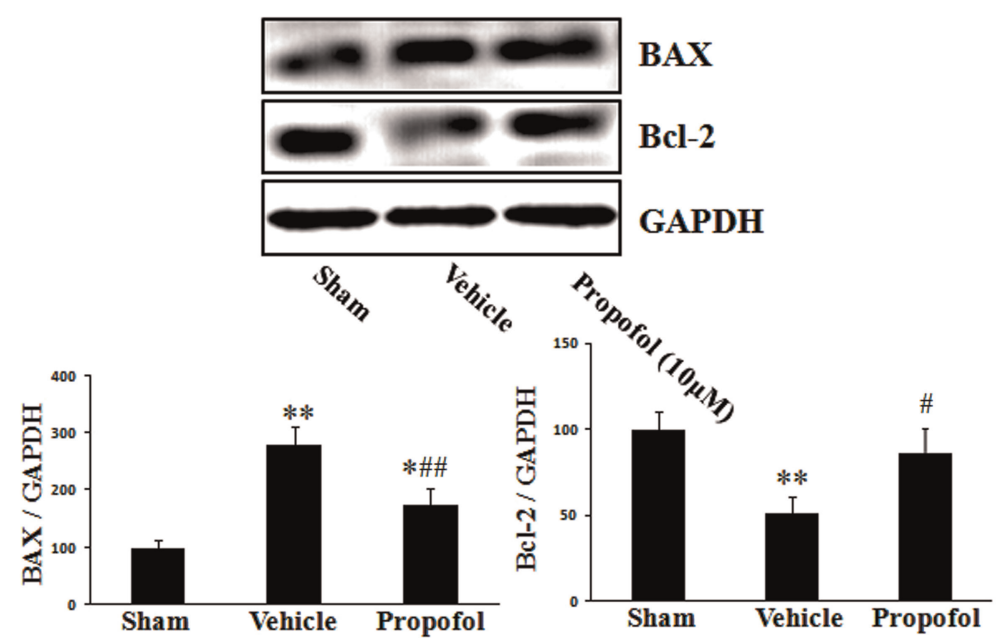

Figure 6. Effect of propofol on burn serum-induced Bax up-regulation and $\mathrm{Bcl}-2$ down-regulation. Compared with the sham group, burn serum exposure led to the upregulation of Bax and downregulation of Bcl-2. Propofol $(10 \mu \mathrm{M})$ pretreatment significantly improved burn serum-induced Bax upregulation and $\mathrm{Bcl}-2$ downregulation. Data are reported as means $\pm S D$ ( $n=3$ in each group). ${ }^{*} \mathrm{P}<0.05$, ${ }^{* *} \mathrm{P}<0.01$, compared to the sham group; ${ }^{\#} \mathrm{P}<0.05$, ${ }^{\#} \mathrm{P}<0.01$ compared to the vehicle group (one-way ANOVA).

inhibited by $10 \mu \mathrm{M}$ propofol pretreatment $(\mathrm{P}<0.01)$, indicating the protective role of propofol against mitochondrial depolarization in burn serum-treated RLMVECs.

\section{Propofol alleviated burn serum-induced mitochondrial dysfunction}

Intracellular ATP levels were used to assess mitochondrial dysfunction. In the vehicle group, the intracellular ATP level was $56.0 \pm 6.4 \%$ of that observed in the sham group $(\mathrm{P}<0.01)$, indicating mitochondrial dysfunction in RLMVECs after exposure to burn serum. Pretreating cells with $10 \mu \mathrm{M}$ propofol increased the ATP level to $81.4 \pm 10.3 \%$ of that of the sham group ( $\mathrm{P}<0.01$, compared with the burn group), revealing that propofol improved burn serum-induced mitochondrial dysfunction (Figure 8).

\section{Propofol reduced burn serum-induced ROS production}

As shown in Figure 9, $10 \mu \mathrm{M}$ propofol pretreatment

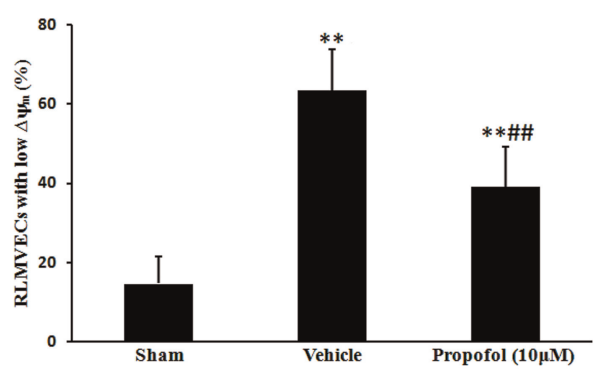

Figure 7. Effect of propofol on burn serum-induced loss of mitochondrial membrane potential $\left(\Delta \psi_{\mathrm{m}}\right)$. Cells with depolarized mitochondria were significantly increased in the vehicle group compared with the sham group. Propofol pretreatment reduced the cells with depolarized mitochondria. RLMVECs: rat lung microvascular endothelial cells. Data are reported as means $\pm S D(n=5$ in each group). ${ }^{* *} \mathrm{P}<0.01$, compared to the sham group; \#\# $\mathrm{P}<0.01$ compared to the vehicle group (one-way ANOVA). decreased the ROS levels from $279.5 \pm 44.8 \%$ of normal values in the vehicle group to $185.8 \pm 32.0 \%$. This result suggested that propofol had a significant anti-oxidative effect on burn injury.

\section{Discussion}

In the present study, we investigated whether propofol could attenuate burn serum-induced endothelial hyperpermeability by inhibiting the activation of intrinsic apoptotic signaling. Burn serum-induced monolayer hyperpermeability was measured in RLMVECs that were exposed to burn serum collected from rats at 1, 2 or $3 \mathrm{~h}$ post-sham/burn for 120 min. Subsequent measurement of TER demonstrated that any of these collected sera could significantly increase monolayer permeability. Serum collected from 3-h postburn rats was used to study the effect of propofol on burn-induced hyperpermeability. In a concentration-dependent experiment, RLMVECs were pretreated with 1,10 and $50 \mu \mathrm{M}$ of

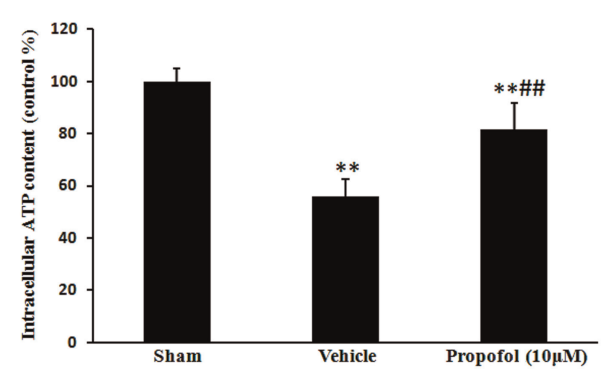

Figure 8. Effect of propofol on burn serum-induced mitochondrial dysfunction. Data are reported as $\%$ of sham values. The intracellular ATP level of cells was significantly decreased in the vehicle group compared with sham cells. Propofol pretreatment significantly increased the intracellular ATP content. Data are reported as means $\pm S D$ ( $n=5$ in each group). ${ }^{* *} P<0.01$, compared to the sham group; ${ }^{\#} \mathrm{P}<0.01$ compared to the vehicle group (oneway ANOVA). 


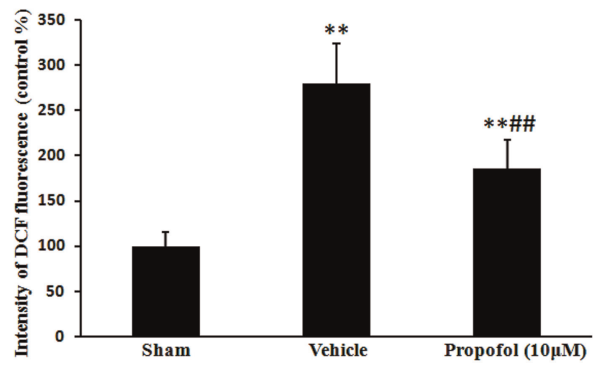

Figure 9. Effect of propofol on burn serum-induced reactive oxygen species (ROS) increase. Data are reported as \% of sham values. Burn serum exposure significantly increased ROS level compared with the sham group. Propofol pretreatment inhibited the burn serum-induced increase of ROS. DCF: dichlorodihydrofluorescein diacetate. Data are reported as means $\pm S D(n=5$ in each group). ${ }^{* *} \mathrm{P}<0.01$, compared to the sham group; ${ }^{\# \# ~} \mathrm{P}<0.01$ compared to the vehicle group (one-way ANOVA).

propofol before applying the burn serum stimulus. We found that burn serum-induced endothelial hyperpermeability was inhibited by pretreatment with 10 or $50 \mu \mathrm{M}$ propofol. These results demonstrated that propofol significantly alleviated burn serum-induced monolayer hyperpermeability.

Some studies have reported that the intrinsic apoptotic signaling cascade is involved in endothelial dysfunction, which may result in vascular hyperpermeability $(5,20)$. Mitochondria activation causes the opening of mPTPs. Subsequently, cytochrome $\mathrm{C}$, apoptosis-inducing factor, and smac are released into the cytosol, and finally caspases are activated $(21,22)$. Caspase- 3 is a key executioner enzyme in apoptosis signal pathways and is activated by apoptosis signaling. Its activation induces the cleavage of a variety of cell adherens proteins, including $\beta$-catenin (23). $\beta$-Catenin acts as a regulator in cadherin-mediated cell-cell adhesion that connects the intracellular domain of VE-cadherin to $\alpha$-catenin, and its cleavage results in disruption of cell-cell adhesion and hyperpermeability (24). In our study, burn serum induced an increase of caspase-3 activity and the release of cytochrome $\mathrm{C}$ and smac into the cytsolic fraction. These alterations were partially alleviated by propofol pretreatment, indicating that propofol inhibited burn seruminduced activation mediated by the intrinsic apoptotic pathway in vitro.

The Bcl family, consisting of anti-apoptotic (Bcl-2, Bcl$\mathrm{xL}$ ) and proapoptotic (BAK, BAX) factors, is highly correlated

\section{References}

1. Senior K. A positive approach to burn care. Lancet 1999; 353 : 1248, doi: 10.1016/S0140-6736(05)66929-2.

2. Kraft R, Herndon DN, Al-mousawi AM, Williams FN, Finnerty CC, Jeschke MG. Burn size and survival probability in paediatric patients in modern burn care: a prospective observational cohort study. Lancet 2012; 379: 1013-1021, doi: 10.1016/ S0140-6736(11)61345-7. with apoptosis (25). The pro-apoptotic members of this family trigger the release of mitochondrial apoptogenic factors into the cytoplasm by regulating mPTP opening. The anti-apoptotic members play opposing roles to prevent apoptosis. Our data suggest that burn serum induces BAX upregulation and $\mathrm{Bcl}-2$ downregulation, both of which can be rescued by propofol treatment. MPTP opening is crucial to apoptotic signaling activation and is responsible for the release of cytochrome $\mathrm{C}$ and smac (26). When mPTP opening is induced, the inner mitochondrial membrane potential $\left(\Delta \psi_{\mathrm{m}}\right)$ dissipates, leading to the loss of mitochondrial functions (e.g., inhibition of energy production and protein translocation into the organelle) (27). In this study, low $\Delta \psi_{\mathrm{m}}$ and decreased intracellular ATP were seen in the cells treated with burn serum, which were restored by propofol, indicating that propofol inhibited burn serum-induced mitochondrial dysfunction.

Oxidative stress can induce the translocation of smac and cytochrome $\mathrm{C}$ into the cytoplasm through mPTPs $(28,29)$; mPTPs are major targets of ROS, which promote opening (30). In this study, ROS were measured because they reflect the effects of burn serum-induced oxidative stress. ROS levels increased in the cells exposed to burn serum, and decreased after propofol treatment. Our results showed that propofol inhibited intrinsic apoptotic signaling through regulating oxidative stress.

In this study, we demonstrated that endothelial hyperpermeability induced by burn serum can be effectively restored by propofol treatment. Propofol may act through the intrinsic apoptotic signaling pathway and mediate burninduced hyperpermeability through mitochondrial membrane depolarization, mitochondrial dysfunction, mitochondrial release of cytochrome $\mathrm{C}$, and activation of caspase 3. Propofol could have positive therapeutic effects through its extensive intervention in this pathway. These observations suggest that propofol holds great promise in preclinical and clinical settings to interfere with vascular hyperpermeability caused by burns.

\section{Acknowledgments}

Research supported by Science and Technology Planning Project of Guangdong Province (\#2010B080701064) and Medical Scientific Research Foundation of Guangdong Province (\#A2012354), China.
3. Lund T, Onarheim H, Reed RK. Pathogenesis of edema formation in burn injuries. World J Surg 1992; 16: 2-9, doi: 10.1007/BF02067107.

4. Latenser BA. Critical care of the burn patient: the first 48 hours. Crit Care Med 2009; 37: 2819-2826, doi: 10.1097/ CCM.0b013e3181b3a08f

5. Whaley JG, Tharakan B, Smith B, Hunter FA, Childs EW. 
(-)-Deprenyl inhibits thermal injury-induced apoptotic signaling and hyperpermeability in microvascular endothelial cells. J Burn Care Res 2009; 30: 1018-1027.

6. Childs EW, Tharakan B, Hunter FA, Tinsley JH, Cao X. Apoptotic signaling induces hyperpermeability following hemorrhagic shock. Am J Physiol Heart Circ Physiol 2007; 292: H3179-H3189, doi: 10.1152/ajpheart.01337.2006.

7. Sinha K, Das J, Pal PB, Sil PC. Oxidative stress: the mitochondria-dependent and mitochondria-independent pathways of apoptosis. Arch Toxicol 2013; 87: 1157-1180, doi: 10.1007/s00204-013-1034-4.

8. Childs EW, Tharakan B, Byrge N, Tinsley JH, Hunter FA, Smythe WR. Angiopoietin-1 inhibits intrinsic apoptotic signaling and vascular hyperpermeability following hemorrhagic shock. Am J Physiol Heart Circ Physiol 2008; 294: H2285-H2295, doi: 10.1152/ajpheart.01361.2007.

9. Tharakan B, Hellman J, Sawant DA, Tinsley JH, Parrish AR, Hunter FA, et al. beta-Catenin dynamics in the regulation of microvascular endothelial cell hyperpermeability. Shock 2012; 37: 306-311, doi: 10.1097/SHK.0b013e318240b564.

10. Shi SS, Yang WZ, Chen Y, Chen JP, Tu XK. Propofol reduces inflammatory reaction and ischemic brain damage in cerebral ischemia in rats. Neurochem Res 2014; 39: 793-799, doi: 10.1007/s11064-014-1272-8.

11. Cui WY, Liu Y, Zhu YQ, Song T, Wang QS. Propofol induces endoplasmic reticulum (ER) stress and apoptosis in lung cancer cell H460. Tumour Biol 2014; 35: 5213-5217, doi: 10.1007/s13277-014-1677-7.

12. Nakajima A, Tsuji M, Inagaki M, Tamura $Y$, Kato M, Niiya A, et al. Neuroprotective effects of propofol on ER stressmediated apoptosis in neuroblastoma SH-SY5Y cells. Eur J Pharmacol 2014; 725: 47-54, doi: 10.1016/j.ejphar.2014. 01.003.

13. Zhang $Y$, Dong $Y, X u Z$, Xie Z. Propofol and magnesium attenuate isoflurane-induced caspase- 3 activation via inhibiting mitochondrial permeability transition pore. Med Gas Res 2012; 2: 20, doi: 10.1186/2045-9912-2-20.

14. Zhang B, Tian M, Zhen Y, Yue Y, Sherman J, Zheng H, et al. The effects of isoflurane and desflurane on cognitive function in humans. Anesth Analg 2012; 114: 410-415, doi: 10.1213/ ANE.0b013e31823b2602.

15. Huang Q, Xu W, Ustinova E, Wu M, Childs E, Hunter F, et al. Myosin light chain kinase-dependent microvascular hyperpermeability in thermal injury. Shock 2003; 20: 363-368, doi: 10.1097/01.shk.0000079425.0000.db.

16. Wang $\mathrm{L}$, Luo $\mathrm{H}$, Chen $\mathrm{X}$, Jiang $\mathrm{Y}$, Huang $\mathrm{Q}$. Functional characterization of S100A8 and S100A9 in altering monolayer permeability of human umbilical endothelial cells. PLoS One 2014; 9: e90472, doi: 10.1371/journal.pone.0090472.

17. Tharakan B, Corprew R, Hunter FA, Whaley JG, Smythe WR, Childs EW. 17beta-estradiol mediates protection against microvascular endothelial cell hyperpermeability. Am J Surg 2009; 197: 147-154, doi: 10.1016/j.amjsurg.2008.10.003.

18. Wang X, Song R, Bian HN, Brunk UT, Zhao M, Zhao KS.
Polydatin, a natural polyphenol, protects arterial smooth muscle cells against mitochondrial dysfunction and lysosomal destabilization following hemorrhagic shock. Am J Physiol Regul Integr Comp Physiol 2012; 302: R805-R814, doi: 10.1152/ajpregu.00350.2011

19. Mishra S, Chatterjee S. Lactosylceramide promotes hypertrophy through ROS generation and activation of ERK $1 / 2$ in cardiomyocytes. Glycobiology 2014; 24: 518-531, doi: 10.1093/glycob/cwu020.

20. Walter DH, Haendeler J, Galle J, Zeiher AM, Dimmeler S. Cyclosporin A inhibits apoptosis of human endothelial cells by preventing release of cytochrome $\mathrm{C}$ from mitochondria. Circulation 1998; 98: 1153-1157, doi: 10.1161/01.CIR.98.12.1153.

21. Duckett CS. IAP proteins: sticking it to Smac. Biochem $J$ 2005; 385: e1-e2, doi: 10.1042/BJ20041800.

22. Luo X, Budihardjo I, Zou H, Slaughter C, Wang X. Bid, a Bcl2 interacting protein, mediates cytochrome $c$ release from mitochondria in response to activation of cell surface death receptors. Cell 1998; 94: 481-490, doi: 10.1016/S0092-8674 (00)81589-5.

23. Steinhusen $U$, Badock $V$, Bauer A, Behrens J, WittmanLiebold B, Dorken B, et al. Apoptosis-induced cleavage of beta-catenin by caspase- 3 results in proteolytic fragments with reduced transactivation potential. J Biol Chem 2000; 275: 16345-16353, doi: 10.1074/jbc.M001458200.

24. Marin N, Zamorano P, Carrasco R, Mujica P, Gonzalez FG, Quezada C, et al. S-Nitrosation of beta-catenin and p120 catenin: a novel regulatory mechanism in endothelial hyperpermeability. Circ Res 2012; 111: 553-563, doi: 10.1161/ CIRCRESAHA.112.274548

25. Yang J, Liu X, Bhalla K, Kim CN, Ibrado AM, Cai J, et al. Prevention of apoptosis by $\mathrm{Bcl}-2$ : release of cytochrome $\mathrm{C}$ from mitochondria blocked. Science 1997; 275: 1129-1132, doi: $10.1126 /$ science.275.5303.1129.

26. Song R, Bian H, Wang X, Huang X, Zhao KS. Mitochondrial injury underlies hyporeactivity of arterial smooth muscle in severe shock. Am J Hypertens 2011; 24: 45-51, doi: 10.1038/ ajh.2010.184.

27. Wang $\mathrm{X}$, Song R, Chen $\mathrm{Y}$, Zhao M, Zhao KS. Polydatin - a new mitochondria protector for acute severe hemorrhagic shock treatment. Expert Opin Investig Drugs 2013; 22: 169179, doi: 10.1517/13543784.2013.748033.

28. Faizi M, Salimi A, Rasoulzadeh M, Naserzadeh $P$, Pourahmad J. Schizophrenia induces oxidative stress and cytochrome $\mathrm{C}$ release in isolated rat brain mitochondria: a possible pathway for induction of apoptosis and neurodegeneration. Iran J Pharm Res 2014; 13: 93-100.

29. Figarola JL, Singhal J, Rahbar S, Awasthi S, Singhal SS. LR90 prevents methylglyoxal-induced oxidative stress and apoptosis in human endothelial cells. Apoptosis 2014; 19: 776-788, doi: 10.1007/s10495-014-0974-3.

30. Simon HU, Haj-Yehia A, Levi-Schaffer F. Role of reactive oxygen species (ROS) in apoptosis induction. Apoptosis 2000; 5: 415-418, doi: 10.1023/A:1009616228304. 